\title{
Patentes e o direito à saúde: análise sobre as discussões de propriedade intelectual na Organização Mundial da Saúde, entre 2006 e 2016
}

Patents and the right to health: an analysis of intellectual property discussions in the World Health Organization, between 2006 and 2016

Patentes y el derecho a la salud: análisis sobre las discusiones de propiedad intelectual em la Organización Mundial de la Salud, entre 2006 y 2016

Lucas Felipe Carvalho Oliveira ${ }^{1}$ Alethele de Oliveira Santos ${ }^{2}$

RESUMO: Objetivo - Analisar as discussões realizadas na OMS sobre propriedade intelectual e saúde pública, no período entre 2006 e 2016. Resultados - Houve destaque às funções sociais da propriedade intelectual, contudo, observado que países em desenvolvimento e menos desenvolvidos não são capazes de se beneficiar de uma maior proteção à propriedade intelectual, pelo que devem utilizar-se das flexibilidades presentes nas normas regulatórias, como o Acordo TRIPS e reafirmadas na Declaração de Doha. Considerações Finais - Observa-se que os debates sobre a propriedade intelectual, em especial acerca produtos farmacêuticos, vem cercada de controvérsias relacionadas ao acesso das populações aos medicamentos essenciais, à promoção da inovação e transferência de tecnologias dos países desenvolvidos aos países em desenvolvimento, Importa assinalar que no contexto brasileiro o reconhecimento de propriedade intelectual promoveu um aumento de custo dos produtos farmacêuticos, em virtude do monopólio, e torna-se um dos elementos de barreira ao acesso e à universalização do direito à saúde.

Palavras-chave: Propriedade Intelectual. Direito à Saúde. Organização Mundial da Saúde. Produtos Farmacêuticos.

ABSTRACT Objective - To analyze the discussions held at WHO on intellectual property and public health, between 2006 and 2016. Results - The social functions of intellectual property were highlighted, however, observing that developing and less developed countries are not able to benefit from protection of intellectual property, so that the flexibilities in regulatory standards, such as the TRIPS Agreement and reaffirmed in the Doha Declaration, should be used. Final Considerations - Discussions on intellectual property, in particular on pharmaceuticals, are surrounded by controversies regarding the access of populations to essential medicines, the promotion of innovation and the transfer of technologies from developed to developing countries, It matters to point out that in the Brazilian context the recognition of intellectual property promoted an

\footnotetext{
1 Graduado em Saúde Coletiva pela UnB e Especialista em Direito Sanitário pela Escola de Governo Fiocruz/Brasília. Email: lucasfelipe250@hotmail.com

2 Doutoranda em Saúde Coletiva pela Universidade de Brasília (UnB). Assessora Técnica do Conselho

Nacional de Secretários de Saúde (Conass).Email: alethele.santos@conass.org.br
} 
increase in the cost of pharmaceutical products, due to the monopoly, and becomes one of the barrier elements to the access and universalization of the right to health.

Keywords: Intellectual Property. Right to Health. World Health Organization. Pharmaceutical Products.

RESUMEN: Objetivo - Analizar las discusiones realizadas en la OMS sobre propiedad intelectual y salud pública, en el período entre 2006 y 2016. Resultados - Hubo destaque a las funciones sociales de la propiedad intelectual, sin embargo, observó que los países en desarrollo y menos desarrollados no son capaces de beneficiarse una mayor protección a la propiedad intelectual, por lo que deben utilizarse las flexibilidades presentes en las normas regulatorias, como el Acuerdo ADPIC y reafirmadas en la Declaración de Doha. Consideraciones finales - Se observa que los debates sobre la propiedad intelectual, en particular sobre productos farmacéuticos, están rodeados de controversias relacionadas con el acceso de las poblaciones a los medicamentos esenciales, la promoción de la innovación y la transferencia de tecnologías de los países desarrollados a los países en desarrollo, señalar que en el contexto brasileño el reconocimiento de propiedad intelectual promovió un aumento de costo de los productos farmacéuticos, en virtud del monopolio, y se convierte en uno de los elementos de barrera al acceso ya la universalización del derecho a la salud.

Palabras-Ilave: Propiedad Intelectual. Derecho a la Salud. Organización Mundial de la Salud. Producto Farmacéutico.

\section{Introdução}

A propriedade intelectual é um conjunto de direitos que incide sobre uma criação do intelecto humano, que pode ser aplicada às obras científicas, artísticas, marcas, desenhos industriais, programas de computador, entre outros produtos do raciocínio e da imaginação, sendo estas criações divididas em duas categorias: direito de autor e propriedade industrial (1).

O direito de propriedade intelectual é, portanto, o conjunto de características jurídicas que delimitam o campo de atuação de um sujeito frente a suas criações, as quais são bens incorpóreos. Existem quatro categorias de propriedade intelectual, a saber, patentes, marcas, direito autoral e direitos conexos, sendo que as duas primeiras são caracterizadas como propriedade industrial (2).

Guimarães (1) considera que é a partir do período renascentista que há o surgimento de novos direitos de propriedade, para além do bem em si, reconhecendo-se socialmente direitos referentes à utilização, à reprodução e ao emprego desses novos bens de direito. Mas somente a partir da Revolução Industrial que o direito de propriedade intelectual ganha os moldes e contornos conhecidos atualmente. 
Há dois objetivos advindos do reconhecimento dos direitos de propriedade intelectual: o primeiro, diz respeito ao estímulo às atividades inventivas, com o intuito unicamente econômico de recuperação do investimento e/ou da exploração por parte do autor do invento/descobrimento; o segundo, a garantia de divulgação das descobertas e inventos por parte de seus criadores favorecendo a utilização e o usufruto por parte da sociedade (1) (2) (3) (4).

Desta forma, para Guimarães (1) "a patente é um título de propriedade temporário, outorgado pelo Estado ao inventor, que garante a exclusividade da exploração da invenção".

Historicamente, o reconhecimento de direito de propriedade intelectual ganha status de direito assegurado pelo Estado a partir de convenções, que possuem como marco a Convenção da União de Paris (CUP), de 1883, e o Acordo sobre Aspectos dos Direitos de Propriedade Intelectual relacionados ao Comércio (Acordo TRIPS), de 1994 (3) (5) (6). As discussões sobre a propriedade intelectual nestes fóruns foram marcadas pela grande diferença de posicionamento entre os países desenvolvidos e os países em desenvolvimento (3) (5) (7).

Cabe ressaltar que a CUP reconhecia os direitos de propriedade intelectual por parte dos Estados que assinaram o tratado, mas dava margem para que as legislações internas definissem o limite do direito de propriedade intelectual e quais produtos estariam assegurados. Desta forma, parte dos países não garantiam o direito a patenteabilidade dos produtos farmacêuticos, aspecto que só passou a mudar a partir dos anos 1960 (3) (5) (7).

Com a criação da Organização Mundial do Comércio (OMC) e da assinatura do Acordo TRIPS em 1994, os países signatários da OMC adotaram medidas paritárias acerca dos direitos de propriedade intelectual e de patentes do setor farmacêutico (3) (5) (6) (7). Ou seja, os países que não possuíam em suas legislações o reconhecimento de patentes e propriedade intelectual passaram a garanti-lo, incluindo-se o reconhecimento à patente de produtos farmacêuticos, incluídos países de capitalismo periférico.

No Brasil, o reconhecimento da propriedade intelectual é assegurado desde a Constituição de 1824, e incorporado a todas as Constituições posteriores, sendo o país, 
também, signatário do acordo da CUP, de 1883, e posteriormente do Acordo TRIPS (4) (5).

O Acordo TRIPS foi internalizado a partir da Lei ำ 9.279, de 14 de maio de 1996, conhecida como a Lei de Propriedade Intelectual (LPI) e regula os direitos e obrigações relativas ao assunto. É importante ressaltar que até a assinatura do Acordo TRIPS e a LPI o Brasil não garantia o direito de patentes de produtos farmacêuticos (5) (6) (8) (9).

Destaca-se que o acesso e o preço de medicamentos estão indiretamente ligados à permissão e ao reconhecimento de patentes sobre produtos farmacêuticos, uma vez que a presença de monopólio, oligopólio e cartéis dificultam o acesso da população aos medicamentos, principalmente àquelas em condições de vulnerabilidade social (5) (10) (11) (12) (13) (14).

No caso brasileiro, observou-se que os preços de medicamentos, enquanto sob vigência das patentes, aproximam-se dos valores máximos permitidos aos consumidores pela Câmara de Medicamentos (CMED), e que quando da expiração da patente, ocorre queda dos preços de medicamentos, que chegam a ficar $10.000 \%$ menores do que o preço máximo permitido (12) (13).

No âmbito internacional, o Brasil liderou embates em diversos organismos, principalmente com os Estados Unidos da América, defendendo a superioridade do interesse público no acesso aos medicamentos em relação à defesa de patentes, principalmente, em virtude dos altos preços de medicamentos do coquetel de antirretrovirais, que, em sua maioria, estavam protegidos por patentes (4) (5).

Desta forma, o Acordo TRIPS foi revisto com a publicação da Declaração de Doha, em 2001, que dispõe sobre a saúde pública e reforça o direito de os países em desenvolvimento utilizarem as flexibilidades presentes no art. 31 do Acordo TRIPS, que trata de "licenças compulsórias", com o objetivo de diminuir os efeitos deletérios das políticas de propriedade intelectual (3) (4) (5) (6) (7) (15).

Nesse ínterim, a OMS, em 2003 criou a Comissão sobre Direitos de Propriedade Intelectual, Inovação e Saúde Pública (CIPIH) (5) (6) (15).

A CIPIH apresentou 60 recomendações, além de dados que demonstram que os argumentos, trazidos pelos países desenvolvidos nas discussões que precederam a assinatura do Acordo TRIPS, de que a propriedade intelectual geraria desenvolvimento 
econômico e maior acesso aos medicamentos, em virtude da ampliação do incentivo privado em Pesquisa, Desenvolvimento \& Inovação (PD\&I), não se tornaram reais (3) (5) (6) (9) (15) (16).

O presente artigo apresenta e analisa as discussões travadas na OMS sobre propriedade intelectual e saúde pública, compreendidas pelo período entre 2006 e 2016.

\section{Metodologia}

Segundo Minayo (17) o primeiro passo de toda pesquisa é a promoção de ampla pesquisa bibliográfica que seja "capaz de projetar luz e permitir a melhor ordenação e compreensão da realidade", desta forma a análise inicial é constituída de pesquisa bibliográfica sobre o tema de propriedade intelectual, patentes e licença compulsória, para constituir pesquisa descritiva, com análise qualitativa, a partir de aferição documental.

O objeto de estudo trata da análise documental dos relatórios da OMS disponíveis no site oficial da instituição, ressaltando que os relatórios disponíveis são de domínio público e qualquer pessoa pode acessá-los de modo livre e desembaraçado. 0 marco temporal adotado foi o período compreendido entre 2006 a 2016, contemplando assim a última década de discussão sobre a temática.

O site WHO-IRIS é o repositório institucional da OMS, no qual estão disponíveis diversos documentos, como resoluções e decisões, livros, relatórios, atas, entre outros e que tem por objetivo o compartilhamento de informações, sendo que IRIS é o acrônimo em inglês para "repositório institucional para compartilhamento de informações" (18).

A seleção dos relatórios deu-se a partir da expressão-chave "Intellectual Property" para a busca documental na biblioteca digital da OMS, com o emprego de dois filtros de assunto: o primeiro que contivesse o objeto patentes, e, o segundo que não constituísse resolução e decisão, sendo desconsiderados quaisquer outros documentos que não fossem relatórios.

Desta forma, a partir da análise documental, foi possível identificar as discussões presentes na OMS sobre propriedade intelectual e patentes de medicamentos, sobre as quais aplicou-se a técnica do Discurso do Sujeito Coletivo (DSC), método criado por Lefèvre \& Lefèvre (19). 
O DSC é "uma proposta de organização e tabulação de dados qualitativos de natureza verbal, obtidos de depoimentos, artigos de jornal, matérias de revistas semanais, cartas, papers, revistas especializadas, etc." (19) considerando sempre que a pessoa ou coletividade "professa, ou adota, ou usa um ou vários discursos sobre o tema" (19).

O DSC difere da proposta qualitativa tradicional, uma vez que, rompe com a lógica quantitativo-classificatória e resgata o discurso como marca de conhecimento dos próprios discursos, reconstruindo, a partir de pedaços dos discursos individuais, discursos-síntese que expressem uma forma de pensar ou uma representação social sobre determinado assunto (19).

Tem por objetivo principal é analisar o material coletado, proveniente de diversas fontes como entrevistas, artigos, cartas, entre outros documentos, retirando-se as ideias centrais e/ou ancoragens, juntamente com as expressões-chave e, a partir de cada uma das expressões-chave, derivadas das ideias centrais e ancoragens similares construir um ou mais discursos-síntese, sempre utilizando a primeira pessoa do singular (19). Desta forma, o discurso construído na primeira pessoa do singular representa a fala de toda uma coletividade, tornando-se "uma forma ou um expediente destinado a fazer a coletividade falar diretamente" (19).

A análise de discurso, a partir do DSC, possibilitou identificar nos documentos da OMS 5 categorias, a saber: (i) Inovação; (ii) Pesquisa e Desenvolvimento; (iii) Difusão e Acesso aos produtos médicos; (iv) Promoção da Inovação; e (v) Direitos de Propriedade Intelectual. Entretanto, para este artigo e conforme disposto em projeto original de pesquisa, interessa especialmente o DSC relacionado com a categoria de Direitos de Propriedade Intelectual.

\section{Resultados}

$\mathrm{Na}$ biblioteca digital da OMS foram identificados 2.454 documentos, a partir da busca pela expressão chave "Intellectual Property". Contudo, com a aplicação dos filtros já apresentados restaram 32 documentos, entre eles, livros, guias, diretrizes e relatórios. Como o objeto de estudo desta pesquisa são os relatórios, foram excluídos os livros, guias e diretrizes. 
Dos 28 relatórios selecionados, 22 eram duplicados, ou seja, o mesmo relatório apresentado em idiomas diferentes. Desta forma, a quantidade de relatórios analisados foram 6 (20) (21) (22) (23) (24) (25), conforme se observa no quadro abaixo:

Quadro 1 - Relatórios Analisados sobre Patentes e Direito de Propriedade intelectual da OMS

\begin{tabular}{|l|c|c|c|}
\hline \multicolumn{1}{|c|}{ Título Ano } & Idioma & Quantidade de \\
páginas
\end{tabular}

Fonte: Organização Mundial da Saúde, elaboração própria, 2017.

Os relatórios analisados referem quatro anos diferentes - 2006, 2007, 2008 e 2009, sendo que a metade deles pertencentes ao ano 2007. Infere-se que o ano de 2007 teve a maior quantidade de relatórios em virtude da publicação do relatório da Comissão sobre Direitos de Propriedade Intelectual, Inovação e Saúde Pública (CIPIH), no ano anterior, e principalmente, em face da recomendação para a elaboração de um plano de ação mundial.

A CIPIH foi instituída em 2003, e após reuniões e análises, tornou público seu relatório em 2006, cujos membros eram professores, ex-ministros e outros atores importantes e relacionados ao assunto de diversos países, desenvolvidos e em 
desenvolvimento, incumbidos de analisar os impactos do Acordo TRIPS na saúde pública mundial.

O plano mundial recomendando pela CIPIH, possuía como principal objetivo estabelecer metas para os estados-membros da OMS, e para a própria OMS, no sentido de promover a inovação em saúde pública, e diminuir os efeitos negativos do maior reconhecimento dos direitos de propriedade intelectual.

O subtópico a seguir, apresenta o discurso-síntese decorrente da análise do Discurso do Sujeito Coletivo, acerca da categoria selecionada: Diretos de Propriedade Intelectual.

\section{Discurso-síntese: Direitos de Propriedade intelectual}

Os direitos de propriedade intelectual têm papel importante a desempenhar na promoção da inovação em matéria dos produtos de atenção médica e nos países que dispõem de capacidade financeira e tecnologia para o seu desenvolvimento e proteção, e principalmente, porque estes países possuem mercados que rendem benefícios para as indústrias farmacêuticas. Nos países em desenvolvimento, a possibilidade de obter uma patente contribui pouco ou nada com a inovação se o mercado é muito pequeno ou a capacidade científica ou tecnológica é inadequada e insuficiente. Assim sendo, o equilíbrio dos custos e dos benefícios das patentes varia entre países, conforme seu nível de desenvolvimento e sua infraestrutura científica e tecnológica.

A proteção mediante patente se atribuiu tradicionalmente a diversas funções, sendo a mais reconhecida a função incentivadora. Tal justificativa se baseia na hipótese de que, na falta de proteção mediante patente, os inventores não poderiam desfrutar dos benefícios que suas criações intelectuais reportariam, o que teria consequências negativas a respeito dos incentivos da inovação para a sociedade e seu conjunto. A justificativa se baseia no pressuposto implícito de aplicação em um contexto econômico e tecnológico no qual se pode fomentar a inovação, sobretudo, por parte do setor privado. Entretanto a validez dessa suposição depende do contexto, pode ser que a suposição seja correta, em geral, nos países desenvolvidos e uns poucos países em desenvolvimento que dispõem do capital e da capacidade inovadora necessários. Em outras palavras, o efeito global dos regimes de propriedade intelectual depende do contexto.

Outra possível função das patentes é a função transacional, intimamente relacionada com a função motivadora descrita acima. A disponibilidade de proteção mediante patente considera uma condição prévia necessária, em alguns casos, para a aparição de novos mercados para os abastecedores de tecnologia e tecnologia especializada. A concessão de direitos de patentes pode limitar a duplicação da atividade inovadora, preservando ao mesmo 
tempo, em alguns casos, incentivos suficientes para o posterior desenvolvimento de produtos de baixo controle do titular da patente.

As patentes também cumprem uma função divulgadora. A divulgação da informação técnica que, do contrário, manter-se-ia em segredo, é um aspecto importante da investigação científica e do desenvolvimento.

Por último, as patentes são valiosas pela sua função de sinalização. A patente pode servir para assinalar a capacidade inovadora de uma empresa e aumentar suas possibilidades de conseguir o capital necessário, especialmente através do financiamento de risco.

Afirma-se, então, que os direitos de propriedade intelectual constituem um incentivo importante para o desenvolvimento de novos produtos para a atenção médica, principalmente, porque com as políticas sobre patentes e licenças, os países deveriam tratar de aumentar ao máximo a disponibilidade de inovações, incluindo instrumentos de pesquisa e plataformas tecnológicas, a fim de desenvolver produtos de interesse para a saúde pública, em particular destinados a combater doenças prevalentes nos países em desenvolvimento. Entretanto, este incentivo por si só não basta para satisfazer a necessidade de desenvolver novos produtos contra doenças, nos casos em que o potencial mercado comercial desses produtos é pequeno e incerto.

Desta forma, os direitos de propriedade intelectual não impedem nem devem impedir que os Estados Membros adotem medidas para proteger a saúde pública. As negociações internacionais sobre as questões relacionadas com os direitos de propriedade intelectual e a saúde devem adotar critérios coerentes com a promoção da saúde pública.

Entretanto, na prática, os efeitos de uma proteção rigorosa da propriedade intelectual sobre o mercado de produtos farmacêuticos são controversos. Restrições suplementares, como as normas do Acordo TRIPS-plus (Acordo sobre Aspectos dos Direitos de Propriedade Intelectual Relacionados ao Comércio), são impostas aos países em desenvolvimento nos acordos bilaterais de livre mercado, assim como estas mesmas normas criam barreiras aos esforços desprendidos pelos países em desenvolvimento, para melhorar o acesso aos produtos de saúde por preço mais acessível.

Defende-se que os tomadores de decisões políticas e os atores sociais interessados na temática entendam completamente as questões relacionadas à execução e à gestão dos direitos de propriedade intelectual, mas a realidade é de falta de recursos humanos especializados em matéria de propriedade intelectual, o que dificulta a utilização eficaz das cláusulas de salvaguarda relativas à saúde pública, com vistas à melhoria do acesso aos produtos de saúde a preços acessíveis.

Ao entender que as indústrias farmacêuticas não se beneficiam de incentivos financeiros e de mercados suficientes para investir em pesquisa e inovação focadas nas doenças que surgem, sobretudo, na região africana e por conseguinte, podem impor preço elevado por medicamentos importados e sob o direito de propriedade intelectual, há que se conectar a função social que a proteção da propriedade intelectual possui, baseada nos argumentos de reinvindicação de maior proteção à esses direitos. 
A OMS tem tentado encontrar o equilíbrio nas questões de propriedade intelectual a partir confecção de um plano de ação mundial para a inovação em saúde pública. As tentativas foram materializadas pela realização de workshop técnico sobre a relação entre vacinas e direitos de propriedade intelectual nos países em desenvolvimento, realizando estudos de campo para avaliar a influência dos direitos e propriedade intelectual na obtenção de vacinas inovadoras de fabricantes locais no Brasil e na Índia, bem como, demais projetos, em andamento, que capacitam recursos humanos na África, América Latina e Ásia.

\section{Discussão}

Barbosa (26) comenta que as funções sociais da propriedade intelectual são: a de identificação do autor, a de estímulo à criação, a econômica e a política. Proner (27), identifica 6 argumentos apresentados na defesa do reconhecimento dos direitos de propriedade intelectual: o da justa recompensa, o estímulo à inovação, o estímulo ao investimento, o estímulo ao desenvolvimento, o combate à pirataria e a transferência de tecnologia.

Oliveira et al, (3), comenta que nos debates que precederam a assinatura do Acordo TRIPS, os argumentos dos países desenvolvidos para a maior proteção dos direitos de propriedade intelectual foram de que haveria um maior incentivo, necessário para a inovação, um maior retorno financeiro e se aceleraria a transferência de tecnologia aos países em desenvolvimento. Entretanto, observou-se que tais argumentos e funções só foram alcançados nos países desenvolvidos. Na prática, nos países em desenvolvimento e menos desenvolvidos a maior proteção aos direitos de propriedade intelectual, no tocante à saúde, geraram entraves e severas barreiras ao acesso das populações destes países aos medicamentos essenciais (3) (27) (28) (29) (30) (31) (32).

Estas barreiras ao acesso decorrem, principalmente, do aumento nos preços destes dos produtos farmacêuticos, em especial os medicamentos, em razão da existência de monopólios, produzidos pelo reconhecimento das patentes no setor (28) (29) (30) (31).

Desta forma, tal como colocado nos debates da OMS sobre propriedade intelectual e saúde pública, as funções benéficas à sociedade só são reais em casos específicos e dependem das circunstâncias de cada país (27). Ressalta-se que a transferência de 
tecnologias, prevista no Acordo TRIPS, utilizada como argumento para a maior proteção dos direitos de propriedade intelectual quase não ocorrem, e se ocorre é onerosa e lenta (27) (28).

As flexibilidades mencionadas nos discursos sobre propriedade intelectual na OMS referem-se, principalmente, em primeiro lugar às licenças voluntárias, que são a cessão dos direitos de patente e propriedade intelectual pelos seus detentores, e em segundo lugar na utilização de licenças compulsórias, quando o detentor do direito de patente e propriedade intelectual não cede os direitos e são utilizados em casos específicos (4) (5) (9).

As licenças compulsórias são mecanismos previstos no Acordo TRIPS, no artigo 31, que permite aos países signatários, seguindo critérios específicos, desrespeitar o direito de patente utilizar os medicamentos fabricados em indústrias nacionais, principalmente, a partir da engenharia reversa (2) (4) (5) (9) (16).

Os critérios para a utilização de licenças compulsórias incidem sobre o uso não exclusivo do objeto de patente, a solicitação prévia de licença voluntária ao detentor da patente, assim como, a utilização por um período determinado (5) (9) (16).

A LPI, em seus artigos 68, 70 e 71, prevê e define os critérios para a utilização de licença compulsória no país, que seriam o exercício abusivo da patente, o abuso de poder econômico, a não-exploração local do produto sob patente, a comercialização insatisfatória, o desenvolvimento tecnológico de aprimoramento do produto sob patente por outro autor que não o detentor do direito, a emergência nacional ou interesse público (5) (7) (9) (16).

O Tribunal de Contas da União (TCU), no acordão n. 1787/2017, que trata do fenômeno da judicialização da saúde, ao analisar medicamentos para doenças raras que estão sob proteção de patentes, considera que o Ministério da Saúde deve utilizarse das licenças compulsórias nos casos em que os fabricantes não quiserem negociar a redução dos preços, a exemplo do embate contra os medicamentos da AIDS (33).

É importante considerar que, no contexto brasileiro, a garantia dos direitos de propriedade intelectual sobre produtos farmacêuticos começou a vigorar em 1997, em virtude da LPI, fato criticado por muitos autores (3) (28) (29) (30) (32), e como apresentado em alguns estudos (29) (30) (31) (35), contribuiu para o aumento do preço 
de medicamentos no Brasil, principalmente, aqueles que compõem o coquetel de antirretrovirais. O mesmo pode dar-se em produtos farmacêuticos de combate a doenças raras e doenças crônicas não-transmissíveis, como o câncer (34), (36).

Por fim, é importante assinalar, que a evolução das discussões sobre os impactos da propriedade intelectual de produtos farmacêuticos em saúde pública em âmbito internacional tem ocorrido na OMS, a OMC, a OMPI (Organização Mundial de Propriedade Industrial), e na ONU (Organização das Nações Unidas), através do Relatório do Painel de Alto-nível de acesso aos medicamentos essenciais.

Bermudez (34), destaca que o acesso a medicamentos e demais tecnologias de saúde, não está mais restrito aos países em desenvolvimento ou menos desenvolvidos, atualmente, apresenta-se com restrição inclusive em países desenvolvidos, assim como não está relacionada ou restrita a um grupo determinado de doenças.

\section{Considerações finais}

O reconhecimento dos direitos de propriedade intelectual de produtos farmacêuticos pelos países em desenvolvimento e menos desenvolvidos é assunto cercado de controvérsias.

Deve-se considerar que passados 23 anos da assinatura do Acordo TRIPS, que enrijeceu as normas relativas à propriedade intelectual, principalmente, aquelas relativas aos produtos farmacêuticos, diversas populações, inclusive de países desenvolvidos, continuam sem acesso aos medicamentos essenciais.

É imperativo que os países em desenvolvimento façam uso das flexibilidades previstas nestes acordos internacionais, principalmente na utilização das licenças compulsórias.

Tal prática foi exitosa no caso brasileiro, que em virtude de diversas pressões estrangeiras no final dos anos 1980, conseguiu acordos favoráveis na compra de medicamentos para o coquetel antirretroviral, a partir da ameaça da utilização de licenças compulsórias.

Ressalta-se, também, que o Brasil dispõe de capacidade industrial suficiente para realizar acordos com as empresas farmacêuticas utilizando-se, quando for o caso, das licenças compulsórias ou ainda da ameaça de sua utilização. 
O uso da alternativa legal pelo Brasil, se fundamenta especialmente, no acesso da população aos medicamentos, de modo adequado e sustentável ao financiamento do Sistema Único de Saúde (SUS), o que pode causar no cenário de incorporações de tecnologias no SUS

\section{Referências:}

1. Guimarães R, Souza LEPFd, Santos LMP. Ciência, tecnologia e pesquisa em saúde. In: Giovanella L, Escorel S, Lobato LdVC, Noronha JCd, Carvalho Ald (orgs). Políticas e sistema de saúde no Brasil. 2. ed. Rio de Janeiro: Fiocruz, 2012, 1100p.

2. Aranha MI. Propriedade Intelectual e Patente Farmacêutica. In: Costa AB, Sousa Júnior JGd, Delduque MC, Oliveira MSdC, Dallari SG (orgs). O Direito Achado na Rua: Introdução Crítica ao Direito à Saúde. Brasília: CEAD/UnB, 2008, 460p.

3. Oliveira MA, et al. Protección de Patentes Farmacéuticas en Brasil: ¿Quién se Beneficia? In: Xepeda Bermudez JA, Oliveira MA (orgs). La Propriedad Intelectual em el Contexto del Acuerdo de la OMC sobre los ADPIC: desafíos para la salud pública. Rio de Janeiro: ENSP, 2006, 191p.

4. Aranha MI. O Palco Regulatório das Patentes Farmacêuticas: Licença Compulsória como Ferramenta Regulatória apoiada em PD\&I. Cad. Ibero-Amer. Dir. Sanit. $2016 \mathrm{Jul} /$ Set;5(3):50-64. Disponível em: http://www.cadernos.prodisa.fiocruz.br/index.php/cadernos/article/view/325/395. [Acesso em: 23.set.2017].

5. Guise MS. Comércio Internacional, Patentes e Saúde Pública. Curitiba: Juruá, 2007, 160p.

6. Carvalho, PLd. Patentes Farmacêuticas e Acesso a Medicamentos. São Paulo: Atlas, 2007, 216p.

7. Figueira Barbosa AL. Preços na Indústria Farmacêutica: Abusos e Salvaguardas em Propriedade Industrial. A questão brasileira atual. In: Picarelli MFS, Aranha MI (orgs.). Política de patentes em saúde humana. São Paulo: Atlas, 2001, 270p.

8. Brasil. Lei 9.279, de 14.05.1996. Regula direitos e obrigações relativos à propriedade industrial. Disponível em:

http://www.planalto.gov.br/ccivil 03/leis/L9279.htm. [Acesso em: 23.set.2017] 
9. Mittelbach MMR. Algumas considerações sobre o sistema de patentes e saúde humana. In: Picarelli MFS, Aranha MI (orgs.). Política de patentes em saúde humana. São Paulo: Atlas, 2001, 270p.

10. Nishijima M. Análise econômica dos medicamentos genéricos no Brasil. [Tese]. São Paulo: Faculdade de Economia, Administração e Contabilidade, Universidade de São Paulo; 2003.

11. Texeira LS. Reajuste de preços administrados no setor saúde. Brasília: Consultoria Legislativa, 2006.

12. Miziara NM. Regulação do mercado de medicamentos: A CMED e a política de controle de preços. [Dissertação]. São Paulo: Faculdade de Direito, Universidade de São Paulo; 2011.

13. Brasil. Tribunal de Contras da União. Relatório de auditoria operacional: Ministério da Saúde, Câmara de Regulação do Mercado de Medicamentos - CMED, Agência Nacional de Vigilância Sanitária - ANVISA. Brasília: Presidência do Tribunal de Contas da União, 2013.

14. Zaire CEF. A relação entre indústria farmacêutica e assistência farmacêutica no âmbito do Sistema único de Saúde (SUS): a compra estadual e municipal de medicamentos no Rio de Janeiro. [Dissertação]. Rio de Janeiro: Instituto de Medicina Social, Universidade Estadual do Rio de Janeiro; 2008.

15. Lima JHdS. Saúde global e política externa brasileira: negociações referentes à inovação e propriedade intelectual. Ciên. Saúde Col. 2017, 22(7):2213-2221.

16. Furtado LR. Licenças compulsórias e legislação brasileira sobre patentes. In: Picarelli MFS, Aranha MI (orgs.). Política de patentes em saúde humana. São Paulo: Atlas, 2001, 270p.

17. Minayo MCdS. O desafio do conhecimento: Pesquisa Qualitativa em Saúde. 11. ed. São Paulo: Hucitec, 2008, 407p.

18. World Health Organization. WHO IRIS: WHO global digital library - online access to WHO published material, 2017. Disponível em: http://apps. who.int/iris/?locale=en. [Acesso em: 14.out.2017].

19. Lefèvre $F$, Lefèvre AMC. O discurso do sujeito coletivo: um novo enfoque em pesquisa qualitativa (desdobramentos). 2. ed. Caxias do Sul, RS: Educs, 2005, 256p. 
20. Organización Mundial de la Salud. Salud pública, innovación y derechos de propiedade intelectual - Informe de la Comisión de Derechos de Propiedad Intelectual, Innovación y Salud Pública. 2006, 268p. Disponível em: http://apps.who.int/iris/bitstream/10665/43462/1/a88440 spa.pdf. [Acesso em: 14.out.2017]

21. Organización Mundial de la Salud, Consejo ejecutivo. Informes sobre los progresos realizados - F. Salud pública, innovación y propiedad intelectual: hacia uma estratégia mundial y plan de acción. $120^{a}$ reunión. 2007, 5p. Disponível em: http://apps.who.int/iris/bitstream/10665/25039/1/B120 ID1-sp.pdf. [Acesso em: 14.out.2017].

22. Organización Mundial de la Salud, Consejo ejecutivo. Salud pública, innovación y propiedad intelectual: hacia uma estrategia mundial y plan de acción - Informe de la Secretaría, 120ª reunión, 2007, 18p. Disponível em: http://apps.who.int/iris/bitstream/10665/25042/1/b120 id4-sp.pdf. [Acesso em: 14.out.2017].

23. Organización Mundial de la Salud. Salud pública, innovación y propiedad intelectual: progresos realizados por el Grupo de Trabajo Intergubernamental - Informe de la Secretaría. 60ª Asamblea Mundial de la Salud, 2007, 9p. Disponível em: http://apps.who.int/iris/bitstream/10665/25689/1/A60 27-sp.pdf. [Acesso em: 14.out.2017].

24. Organización Mundial de la Salud. Informe del Grupo de Trabajo Intergubernamental sobre Salud Pública, Innovación y Propiedad Intelectual. 61 Asamblea Mundial de la Salud, 2008, 58p. Disponível em: http://apps.who.int/iris/bitstream/10665/26219/1/A61 9-sp.pdf. [Acesso em: 14.out.2017].

25. Organisation mondiale de la Santé, Comité Régional de L'Afrique. Santé publique, innovation et propriété intellectuelle: perspectives régionales pour la mise en oeuvre de la stratégie et du plan d'action mondiaux. 59a Session Kigali, 2009, 8p. Disponível em: http://apps.who.int/iris/bitstream/10665/2063/1/afr rc59 6 fr.pdf. [Acesso em 14.out.2017].

26. Barbosa CR. Propriedade Intelectual: introdução à propriedade intelectual como informação. Rio de Janeiro: Elsevier, 2009, 196p.

27. Proner C. Propriedade Intelectual: para uma outra ordem jurídica possível. São Paulo: Cortez, 2007, 91p. Disponível em: http://bibliotecavirtual.clacso.org.ar/ar/libros/varios/Proner 2007.pdf. [Acesso em 20.nov.2017]. 
28. Barbieri JC, Chamas $\mathrm{Cl}$. O acordo sobre direitos de propriedade intelectual relacionados ao comércio (TRIPs) e as políticas públicas de saúde e de defesa da biodiversidade. REAd, 2008, 14(1):25-49. Disponível em:

http://gvpesquisa.fgv.br/sites/gvpesquisa.fgv.br/files/arquivos/barbieri chamas 2008 oacordo-sobre-direitos-de-pro 1325.pdf. [Acesso em 20.nov.2017].

29. Chaves GC, et al. Estratégias de redução de preços de medicamentos para aids em situação de monopólio no Brasil. Rev. Saúd. Públ., 2015, 49: 1-10. Disponível em: http://www.scielo.br/pdf/rsp/v49/pt 0034-8910-rsp-S0034-89102015049005459.pdf. [Acesso em 20.nov.2017].

30. Jannuzzi AH, Vasconcellos AG, Souza CGd. Especificidades do patenteamento no setor farmacêutico: modalidades e aspectos da proteção intelectual. Cad. Saúd. Públ., 2008, 24(6): 1205-1218. Disponível em: http://www.scielo.br/pdf/csp/v24n6/02.pdf. [Acesso em 20.nov.2017].

31. Stamford A, Cavalcanti M. Decisões judiciais sobre acesso aos medicamentos em Pernambuco. Rev. Saúd. Públ., 2012, 46(5): 791-799. Disponível em: http://www.scielo.br/pdf/rsp/v46n5/05.pdf. [Acesso em: 20.nov.2017].

32. Chaves GC, et al. A evolução do sistema internacional de propriedade intelectual: proteção patentária para o setor farmacêutico e acesso a medicamentos. Cad. Saúd. Públ., 2007, 23(2):257-267. Disponível em: http://www.scielo.br/pdf/csp/v23n2/02.pdf. [Acesso em: 20.nov.2017].

33. Brasil. Tribunal de Contas da União. Acórdão 1787/2017: Relatório de Auditoria: Ministério da Saúde. Relator: Bruno Dantas. Brasília: Presidência do Tribunal de Contas da União, 2017. Disponível em:

https://contas.tcu.gov.br/pesquisaJurisprudencia/\#/detalhamento/11/\%252a/NUMACOR DAO\%253A1787\%2520ANOACORDAO\%253A2017/DTRELEVANCIA\%2520desc\%252 C\%2520NUMACORDAOINT\%2520desc/false/1/false. [Acesso em: 23.set.2017]

34. Bermudez J. Comtemporary challenges on access to medicines: beyond the UNSG High-Level Panel. Ciênc. Saúd. Col., 2017, 22(8): 2435-2439. Disponível em: http://www.scielo.br/pdf/csc/v22n8/1413-8123-csc-22-08-2435.pdf. [Acesso em 20.nov.2017].

35. Jannuzzi AHL, Vasconcellos AG. Quanto custa o atraso na concessão de patentes de medicamentos para a saúde no Brasil? Cad. Saúd. Públ., 2017, 33(8):1-5. Disponível em: http://www.scielo.br/pdf/csp/v33n8/1678-4464-csp-33-08-e00206516.pdf. [Acesso em: 20.nov.2017].

36. Diniz D. Assistência Farmacêutica do SUS. Supremo Tribunal Federal, Notas Taquigráficas, 2009. Disponível em: 
Cadernos Ibero-Americanos

de Direito Sanitário

Cuadernos Iberomericanos

de Derecho Sanitario

http://www.stf.jus.br/arquivo/cms/processoAudienciaPublicaSaude/anexo/Debora Diniz. pdf. [Acesso em: 20.nov.2017].

Submetido em: 20.12.2017

Aprovado em: 26.12.2017

\section{Como citar este artigo:}

Oliveira LFC, Santos AO. Patentes e o direito à saúde: análise sobre as discussões de propriedade intelectual na Organização Mundial da Saúde, entre 2006 e 2016. Revista Cadernos Ibero-Americanos de Direito Sanitário. 2017 out./dez, 6(4): . 130-146 